\title{
Mood Influences Supraspinal Pain Processing Separately from Attention
}

\author{
Chantal Villemure and M. Catherine Bushnell \\ Alan Edwards Centre for Research on Pain, McGill University, Montréal, Québec, Canada H3A 2B2
}

\begin{abstract}
Studies show that inducing a positive mood or diverting attention from pain decreases pain perception. Nevertheless, induction manipulations, such as viewing interesting movies or performing mathematical tasks, often influence both emotional and attentional states. Imaging studies have examined the neural basis of psychological pain modulation, but none has explicitly separated the effects of emotion and attention. Using odors to modulate mood and shift attention from pain, we previously showed that the perceptual consequences of changing mood differed from those of altering attention, with mood primarily altering pain unpleasantness and attention preferentially altering pain intensity. These findings suggest that brain circuits involved in pain modulation provoked by mood or attention are partially separable. Here we used functional magnetic resonance imaging to directly compare the neurocircuitry involved in mood- and attention-related pain modulation. We manipulated independently mood state and attention direction, using tasks involving heat pain and pleasant and unpleasant odors. Pleasant odors, independent of attentional focus, induced positive mood changes and decreased pain unpleasantness and pain-related activity within the anterior cingulate (ACC), medial thalamus, and primary and secondary somatosensory cortices. The effects of attentional state were less robust, with only the activity in anterior insular cortex (aIC) showing possible attentional modulation. Lateral inferior frontal cortex [LinfF; Brodmann's area (BA) 45/47] activity correlated with moodrelated modulation, whereas superior posterior parietal (SPP; BA7) and entorhinal activity correlated with attention-related modulation. ACC activity covaried with LinfF and periacqueductal gray activity, whereas aIC activity covaried with SPP activity. These findings suggest that separate neuromodulatory circuits underlie emotional and attentional modulation of pain.
\end{abstract}

Key words: pain; fMRI; attention; emotion; odor; heat

\section{Introduction}

Attention and emotion impart a value system to sensory processing, allowing the CNS to mold sensory experience into a subjective landscape (Mesulam, 1998). Experimental and clinical studies show that diverting attention from pain and inducing a positive mood usually decrease pain perception, whereas focusing on pain or inducing a negative mood increases it (Villemure and Bushnell, 2002).

Imaging studies of attentional pain modulation commonly show that decreased pain during distraction is paralleled by decreased activity in thalamocortical ascending pain pathways (Apkarian et al., 2005). Such areas include thalamus, primary and secondary somatosensory cortices (S1, S2), insular cortex (IC), and anterior cingulate cortex (ACC) (Bushnell et al., 1999; Frankenstein et al., 2001; Longe et al., 2001; Bantick et al., 2002; Brooks et al., 2002; Hoffman et al., 2004; Seminowicz et al., 2004; Buffington et al., 2005; Wiech et al., 2005; Dunckley et al., 2007). Brain areas actively involved in modulating pain transmission

\footnotetext{
Received Aug. 12, 2008; revised Dec. 1, 2008; accepted Dec. 4, 2008.

This work was supported by National Institutes of Health Grant 1-R01-NS44036-01. We thank Nazma Mohammed for skilled assistance at all stages of data acquisition; André Cormier, Nicole Fauteux, and Louise Marcotte for expert MRI data acquisition; and Mike Ferreira for expert support with data analysis. We also thank Petra Schweinhardt for valuable comments on a previous version of this manuscript.

Correspondence should be addressed to Chantal Villemure, Alan Edwards Centre for Research on Pain, McGill University, Strathcona Anatomy and Dentistry Building, 3640 University Street, Room M-19, Montréal, Québec Canada H3A 2B2. E-mail: chantal.villemure1@mcgill.ca.

D0I:10.1523/JNEUROSCI.3822-08.2009

Copyright $\odot 2009$ Society for Neuroscience $\quad$ 0270-6474/09/290705-11\$15.00/0
}

during distraction from pain have been less studied. Existing reports suggest that periacqueductal gray (PAG), ACC, orbitofrontal cortex (OFC), and posterior parietal cortex (PPC) are involved (Peyron et al., 1999; Petrovic et al., 2000; Tracey et al., 2002; Valet et al., 2004).

Nevertheless, most of these studies have not measured or controlled for simultaneous changes in the subjects' emotional state or arousal evoked by the stimuli and/or tasks creating the distraction. In some cases, scans were compared during a pain-alone condition and a condition in which pain was presented along with another sensory stimulus (Longe et al., 2001; Brooks et al., 2002; Hoffman et al., 2004). Other studies presented pain with and without a demanding cognitive task (Petrovic et al., 2000; Frankenstein et al., 2001; Bantick et al., 2002; Seminowicz et al., 2004; Valet et al., 2004; Buffington et al., 2005). Either way, the level of arousal, anxiety, and/or mood could differ between conditions, contributing to the findings.

Imaging studies directly addressing emotional pain modulation are fewer. One study evaluated the influence of anxiety on pain perception (Ploghaus et al., 2001). High anxiety increased pain and evoked more activity in entorhinal cortex (ERC), mid insular cortex (midIC), and perigenual cingulate. Another study showed that nonpainful esophageal stimulation evoked more ACC activity in a fearful than in a neutral emotional context (Phillips et al., 2003). Furthermore, high fear increased discomfort and anxiety ratings as well as brain activation within ACC, an- 
terior insular cortex (aIC), and Brodmann's area (BA) 45 more than low fear. Neither study measured or controlled for possible concurrent changes in the subjects' attentional state.

We previously showed differential pain modulation by mood and attention, with mood modifying preferentially pain unpleasantness and attention affecting mainly pain intensity (Villemure et al., 2003). Consistently, other studies show that mood selectively alters pain affect (Zelman et al., 1991) and pain unpleasantness is more strongly affected by emotions than pain intensity (Rainville et al., 2005). Together, these studies suggest that emotions and attention alter pain by invoking partially separable neuromodulatory circuits. To test this hypothesis, we directly compared changes in neural activity associated with emotional and attentional pain modulation, using the paradigm that permitted us to dissociate the perceptual effects of these manipulations (Villemure et al., 2003).

\section{Materials and Methods \\ Subjects}

Fourteen subjects (five males) between 18 and 28 years of age (mean, 23; SD, 3 ) completed the study and were paid for their participation. The study was approved by the McGill University Institutional Review Board, and written informed consent was obtained from each subject. Potential subjects were included if they demonstrated attentional or emotional modulations in a screening session using our experimental task. Exclusion criteria were the same as in our previous study (Villemure et al., 2003), with the addition of significant claustrophobia and other magnetic resonance imaging (MRI)related contraindications. Subjects were instructed not to wear scented products.

\section{General procedure}

Written consent was obtained, olfactory function was evaluated (for details, see Villemure et al., 2003), and olfactory and thermal stimuli were chosen for each subject. The specific temperatures were determined individually to produce moderate pain in the absence of odors, and odorants were chosen individually to insure highly pleasant and unpleasant valences. Subjects then practiced the intensity discrimination task involving either the olfactory or thermal stimuli, to direct attention to the thermal or olfactory modality, while simultaneously manipulating odor hedonics. Subjects demonstrating attentional or emotional modulation of pain perception in the discrimination task were scheduled for their scanning session on a separate day. On the scanning day, in-scanner ventilation was stopped to prevent odor dispersion. An anatomical scan was first acquired, followed by five functional runs. In the first run, subjects received alternating warm and painful heat stimuli. The other runs were devoted to the four conditions of the intensity discrimination task described below.

\section{Painful heat stimuli}

A temperature that evoked moderate pain in the absence of the experimental odors was chosen for each subject, by presenting two ascending series of

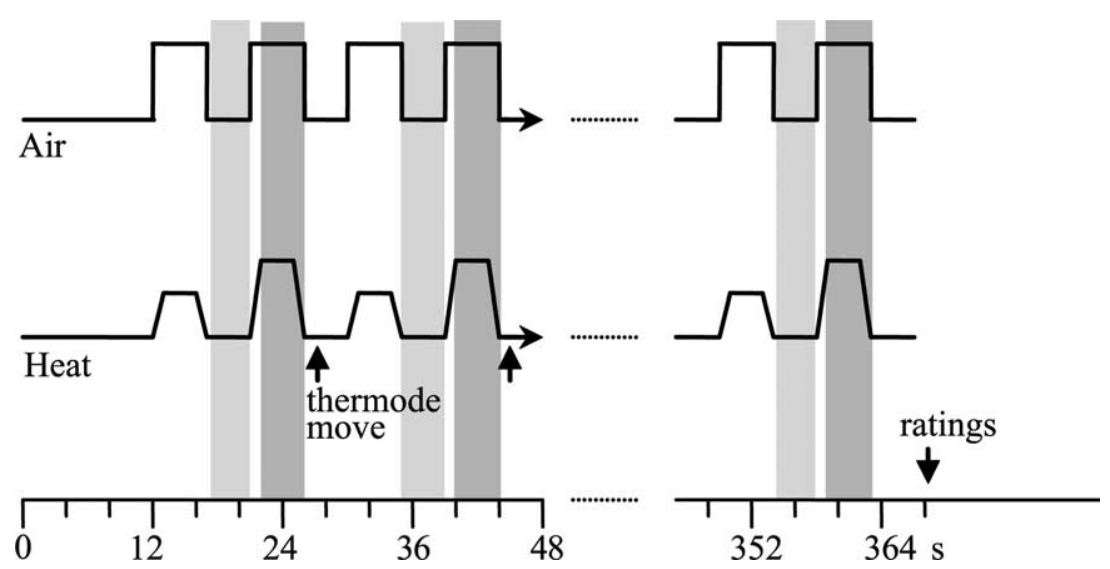

Figure 1. Alternating warm/pain task. In this task, subjects received 20 warm $\left(40^{\circ} \mathrm{C}\right.$ ) and 20 painfully hot $(3 \mathrm{~s} \mathrm{plateau)} \mathrm{stimuli}$ in an alternating manner separated by a $4 \mathrm{~s} I S I$ in which the temperature was $38^{\circ} \mathrm{C}$. Three areas of the inner calf were used for the presentation of the heat stimuli. The thermode was moved from one area to the next after each warm and painful heat pair. Puffs the end of the trial (see Materials and Methods for details). Because the baseline temperature and the rise/fall time were constants (38 and $10^{\circ} \mathrm{C} / \mathrm{s}$, respectively), the total duration of the task varied according to the temperatures used (higher painful temperatures resulted in longer duration). The shadowed boxes represent the time periods analyzed for brain activations. Periods of baseline heat when the thermode was not moved (pale gray boxes) were subtracted from painful heat periods (dark gray boxes).

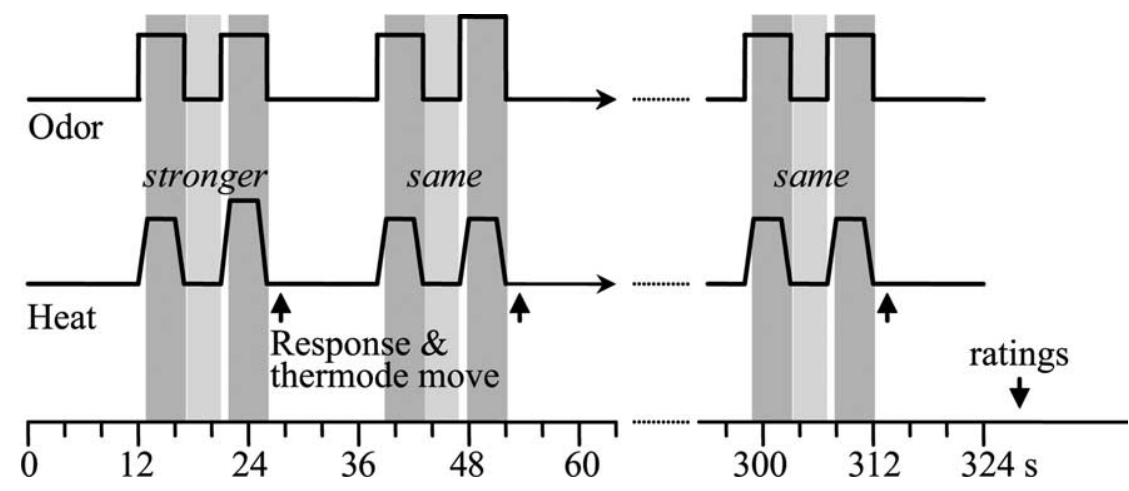

Figure 2. Intensity discrimination task. For this task, both painful heat and odorants (pleasant or unpleasant) were delivered simultaneously. The thermode was moved after each pair of stimuli to another of the three regions of the inner calf. In the example shown here, the subjects attended the painful heat and performed the heat intensity discrimination task, evaluating whether the second stimulus of the pair was stronger or the same intensity as the first after each pair. Twelve discriminations were performed in each of the following four conditions: (1) attending heat in the presence of a good odor (AHGO); (2) attending heat in the in the presence of painful heat $(A O B 0)$. The order was counterbalanced between subjects. At the end of the trial, subjects gave their ratings of pain intensity and unpleasantness, odor intensity and hedonics, mood, and anxiety (see Materials and Methods for of the task varied according to the temperatures used (higher temperatures resulted in longer duration). The shadowed boxes represent the time periods analyzed for brain activations reported in this study. Periods of baseline with a touch component (pale gray boxes) were subtracted from periods of painful heat (dark gray boxes).

discrete temperatures ranging from 36 to $50^{\circ} \mathrm{C}$ to three areas of the inner left calf using a $9 \mathrm{~cm}^{2}$ contact thermode (TSA II NeuroSensory analyzer; Medoc Advanced Medical System). Each stimulus had a plateau time of $3 \mathrm{~s}$ and a rise/fall time of $10^{\circ} \mathrm{C} / \mathrm{s}$ leading to an approximate stimulus length of $5 \mathrm{~s}$. After each heat pulse, subjects rated stimulus intensity and pleasantness/unpleasantness, and a temperature was identified that the subject rated $\sim 5$ on the intensity scale $(0-10)$. A second heat stimulus was identified that subjects could distinguish from the first with $\sim 80 \%$ accuracy to be used in the discrimination task. This stimulus was typically $1^{\circ}$ more. In the discrimination task described below, the lower painful temperature was always used as the first stimulus of the pair, whereas the higher painful temperature appeared pseudo-randomly in $50 \%$ of cases as the second stimulus of the pair. Subjects were never notified that only two painful temperatures would be used in the experimental tasks. 
Table 1. Thresholds for the different ROls

\begin{tabular}{lccc}
\hline Brain area & Total volume $\left(\mathrm{mm}^{3}\right)$ & Threshold $t$ for peak & Threshold volume $\left(\mathrm{mm}^{3}\right)$ for cluster with $t>2.5$ \\
\hline Thresholds for pain processing-related areas & & & \\
$\quad$ S1 leg area & 4229 & 3.2622 & 324 \\
S2 & 9177 & 3.4989 & 268 \\
alC & 6968 & 3.4171 & 424 \\
Entire IC & 14,509 & 3.6369 & 259 \\
ACC & 6647 & 3.4030 & 201 \\
Perigenual cingulate & 4840 & 3.3061 & 266 \\
$\quad$ Thalamus & 6892 & 3.3144 & 93 \\
Thresholds for pain modulator areas & 2439 & & n.a. \\
ERC & 385 & 3.0855 & 397 \\
PAG & 12,906 & 2.4350 & 320 \\
Superior parietal & 9000 & 3.6017 & 3.4947 \\
Inferior frontal cortex including lateral OFC
\end{tabular}

n.a., Not applicable.

\section{Odor stimuli}

Subjects evaluated six odors diluted to $0.1-5 \% \mathrm{v} / \mathrm{v}$ in an appropriate inodorous solvent (distilled water or propylene glycol). Different types of odors were presented including pyridine, which has a smell reminiscent of rotten fish at the concentration used (Sigma-Aldrich Canada), and cosmetic-grade fragrance oils with food and floral scents: China rain, creamsicle, lemon meringue, mint, and violet (K \& W Specialties). For the odor selection, the diluted fragrances $(10 \mathrm{ml})$ were presented in $60 \mathrm{ml}$ amber bottles identified with numbers. Using the pleasantness/unpleasantness ratings, the most preferred and disliked odors were chosen.

During the discrimination task (described below), $5 \mathrm{~s}$ odor pulses were delivered by a computer-controlled odor generator (Knosys Olfactometers). A transistor-transistor logic pulse generated by the thermode at the beginning of the heat pulse triggered the opening of the appropriate valve of the olfactometer, resulting in synchronized presentation of the thermal and olfactory stimuli. An air flow of $0.41 / \mathrm{min}$ was used. The odorized air from each independent channel reached the subjects through a 10-m-long Teflon-lined tube. Each tube was connected to a separate leg of a glass manifold. A separate opening of the manifold connected to a vacuum pump that operated between presentations to prevent lingering odors. A Y-shape glass piece was secured with tape just below the subject's nostrils for birhinal stimulation. A $10 \times 21 \mathrm{~cm}$ Teflon sheet was loosely taped over the subject's nose and mouth to prevent odor dispersion. Subjects were instructed to close their mouth and to breathe normally through their nose. The concentrations used in the discrimination task were 0.1 and $1 \% \mathrm{v} / \mathrm{v}$ for pyridine, 0.5 and $5 \% \mathrm{v} / \mathrm{v}$ for mint, and 0.3 and $3 \% \mathrm{v} / \mathrm{v}$ for the other odors. The stronger concentration was always used as the second stimulus of the pair, whereas the weaker concentration appeared pseudo-randomly in $50 \%$ of cases as the first stimulus of the pair. None of the odors used were judged as pungent or irritating.

\section{Measures}

Numerical rating scales (NRSs) of $0-10$ were used to evaluate the intensity and hedonic quality (pleasantness/unpleasantness) of the odor and painful stimuli. We stressed the differences between stimulus intensity and pleasantness/unpleasantness using explanations adapted from Price et al. (1983). Mood and anxiety were also assessed with similar scales. The odor intensity scale was anchored with 0 (no odor) and 10 (extremely intense). The pain intensity scale was anchored with 0 (no pain) and 10 (most intense pain tolerable). The pleasantness scale was used for odor evaluation and anchored with 0 (neutral) and 10 (extremely pleasant). The unpleasantness scale was used for both the odor and painful stimuli and anchored with 0 (neutral) and 10 (extremely unpleasant). The good and bad mood scales were anchored with 0 (neutral) and 10 (extremely good or bad). The calmness and anxiety scales were anchored with 0 (neutral) and 10 (extremely calm or anxious). Subjects gave their ratings verbally.

\section{Experimental tasks}

Alternating warm/pain task. In this task, depicted in Figure 1, subjects were asked to attend 20 warm $\left(40^{\circ} \mathrm{C}\right)$ and 20 painfully hot (the lowest temperature used in the discrimination task) stimuli presented in an alternating manner with a $4 \mathrm{~s}$ interstimulus interval (ISI). Puffs of unscented air (5s) were delivered with each thermal stimulus. After the termination of the scan, subjects were asked to verbally give their overall ratings of pain intensity and unpleasantness, odor intensity and hedonics, mood, and anxiety/calmness using the scales described above.

Intensity discrimination/attention task. For this task, both painful heat and an odorant were presented simultaneously, but on some trials subjects performed a heat-intensity discrimination task, whereas on other trials they performed an odor-intensity discrimination task, thus ensuring that they attended to one or the other sensory modality. In addition to manipulating direction of attention, in this task the hedonic value of the odorant was manipulated so that a pleasant odor was presented in half the trials and an unpleasant odor was presented in the other half. Figure 2 provides a depiction of the paradigm. Stimuli of a pair were separated by $4 \mathrm{~s}$, and the interpair interval was set at $12 \mathrm{~s}$. Subjects received four separate conditions, each including 12 discriminations lasting $\sim 5 \mathrm{~min}$. In one condition, subjects attended to the intensity of the noxious heat in the presence of the good odor (AHGO), and in another, in the presence of the bad odor (AHBO). A third and fourth condition involved attending to the intensity of the good (AOGO) or bad (AOBO) odor in the presence of noxious thermal stimuli. The order of the conditions was counterbalanced across subjects. In $50 \%$ of cases (pseudo-random), both stimuli of the pair were the same intensity. The subjects' task was to decide whether the second stimulus of the pair was stronger or the same intensity as the first stimulus. They used a nonverbal code to give their answer (closed their left fist for "same" and a thumb up for "stronger"). They received nonverbal feedback about their performance after each discrimination (the experimenter tapped the subject's ankle once to indicate that the answer was correct and three times to indicate a wrong answer). These nonverbal signals were given during time periods excluded from functional magnetic resonance imaging (fMRI) analysis. To maximize the attentional demand of the discrimination tasks, we chose stimulus intensity differences that led to a submaximal performance (we aimed for $80 \%$ correct). Immediately after the 12th discrimination of each condition, once the scan acquisition was over, subjects provided the experimenter with verbal ratings of overall pain intensity and unpleasantness, odor intensity and hedonics, mood, and anxiety/calmness using the scales described above.

\section{Statistical analysis of behavioral data}

All statistical analyses were performed with SPSS 15.0 for Windows (SPSS). A significance level of $p<0.05$ was adopted for all analyses. We used the general linear model with two repeated measures with two levels each (ATTENTION: pain or odor; ODOR VALENCE: good or bad) for the separate analyses of the dependent variables performance, pain intensity, pain unpleasantness, mood, and anxiety. The Tukey's honest significance difference (HSD) was used for post hoc analyses whenever appropriate. In addition, we used stepwise linear regression analysis to examine the model that best predicted changes in pain unpleasantness ratings. The independent variables used in the regression model were 
changes in odor hedonics, mood, and anxiety. Pain unpleasantness ratings in the GO condition were subtracted from the pain unpleasantness ratings obtained in the $\mathrm{BO}$ condition. Odor hedonics, mood, and anxiety ratings obtained in the $\mathrm{BO}$ condition were subtracted from those obtained in the $\mathrm{GO}$ conditions. A positive number reflected an improvement in pain, odor hedonics, mood, or anxiety associated with the pleasant odorant.

\section{MRI acquisition and general procedures}

A 1.5 tesla MRI scanner (Siemens) with a standard head coil was used. Anatomical scans were collected using a high-resolution, T1-weighted anatomical protocol [repetition time (TR), 22 ms; echo time (TE), $9.2 \mathrm{~ms}$; flip angle, $30^{\circ}$; field of view, $256 \mathrm{~mm}^{2}$ ]. Functional scans were collected using a blood oxygenation leveldependent (BOLD) protocol with a $\mathrm{T}^{*}$ weighted gradient echoplanar imaging sequence (TR, $4 \mathrm{~s}$; TE, $50 \mathrm{~ms}$; flip angle, $90^{\circ}$ ). The scanning planes were oriented parallel to the line between the anterior and posterior commissures. Thirty-six $4 \mathrm{~mm}$ slices were acquired covering the brain from the top of the cortex down to the base of the cerebellum.

Global searches for pain-evoked activation Functional data were first corrected for motion by registering all volume acquisitions to the third volume in the scan and then spatially smoothed with a $6 \mathrm{~mm}$ full-width at halfmaximum Gaussian kernel. The first three volumes were excluded to ensure steady-state magnetization. Both the anatomical and functional volumes were resampled into standard stereotaxic space based on the Montreal Neurological Institute (MNI) 305 template (Collins et al., 1994). Therefore, all activations are reported using MNI coordinates. Functional images were processed, and $t$-statistic images representing changes in BOLD contrast were generated with fMRISTAT-MULTISTAT software developed at the MNI (Montreal, Canada; available at http://www.math.mcgill.ca/keith/ BICstat). The statistical analysis of the fMRI data was based on a linear model with correlated errors (Worsley et al., 2002). Temporal drift was removed by adding polynomial covariates in the frame times, up to degree 3 , to the design matrix. All $t$-statistic images were thresholded ( $p=0.05)$ using a Bonferroni correction based on the number of voxels in the search region or the random field theory, whichever gave the minimum threshold (Worsley et al., 1996; Cao, 1999).

The volume of the whole-brain gray matter was estimated to be $1,200,000 \mathrm{~mm}^{3}(18,750$ voxels), yielding a threshold $t$ value of 4.8 for the global search.

\section{Directed search analysis}

Based on a review of previous studies (Apkarian et al., 2005), directed searches of pain processing-related areas were performed in $\mathrm{S} 1$ leg area, S2, aIC, entire IC, dorsal ACC, perigenual cingulate, and thalamus. For pain modulatory areas, directed searches were performed in regions previously shown to be activated
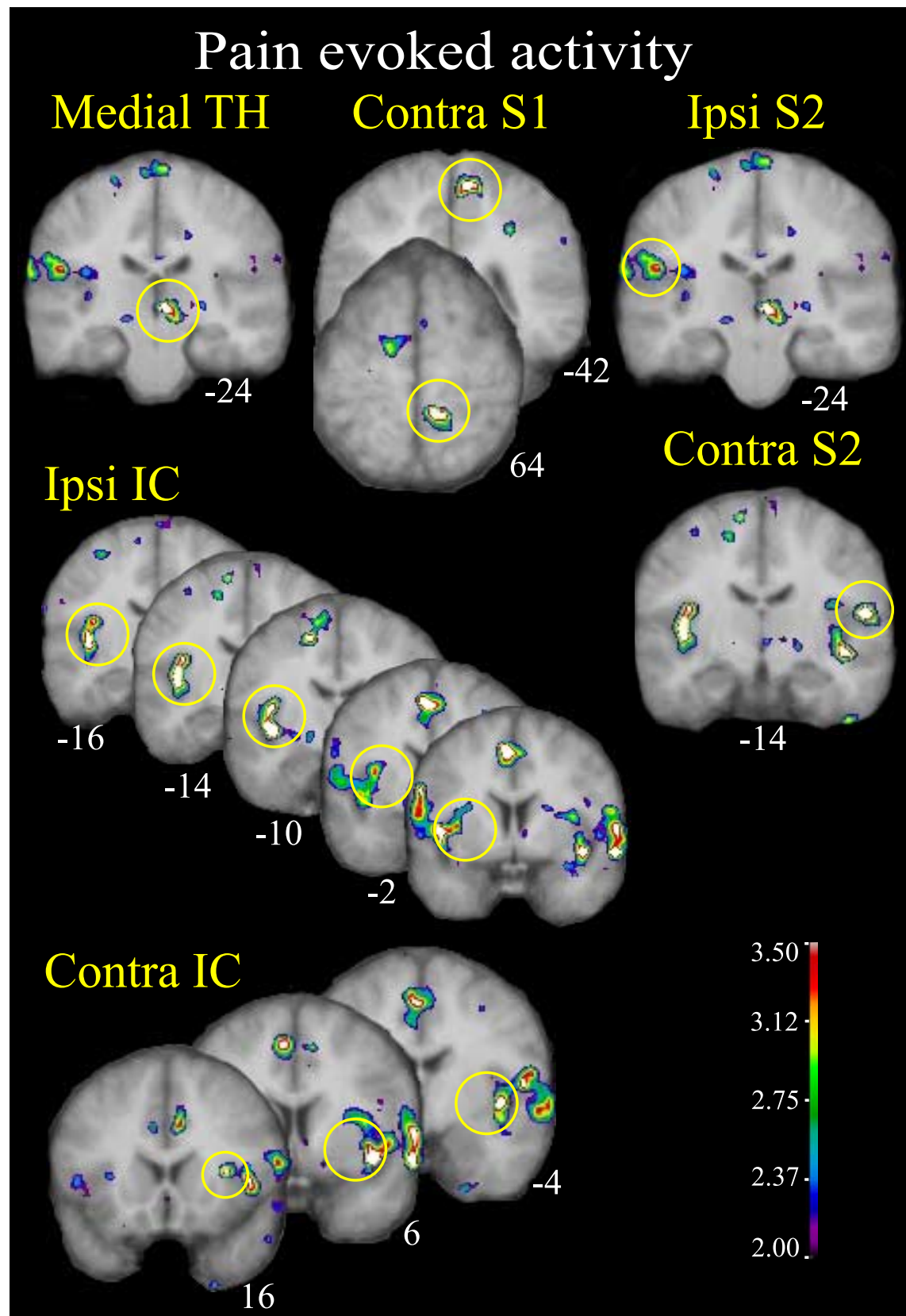

2.75

2.37

2.00

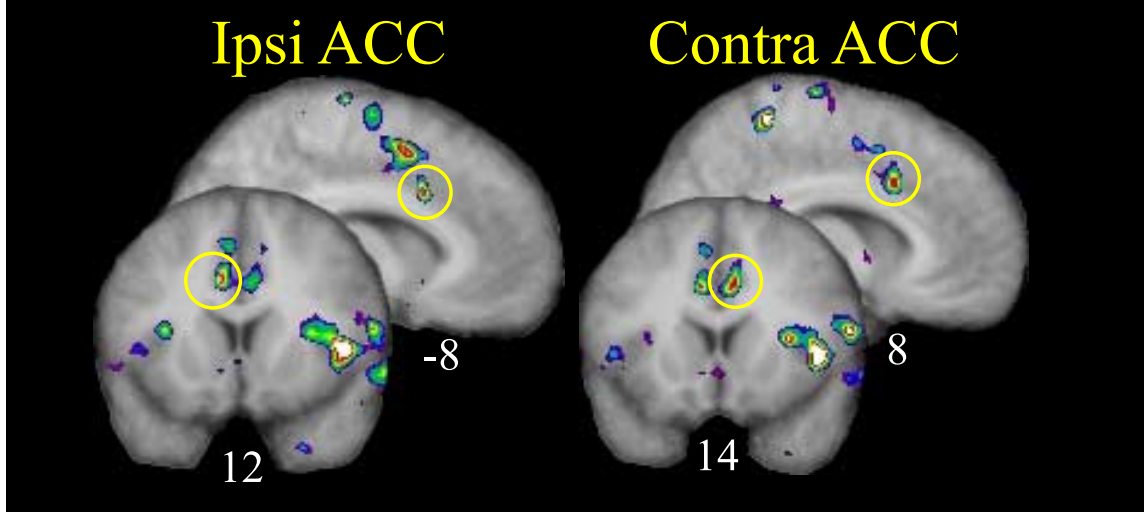

Figure 3. Thalamic and cortical activity evoked by heat pain in the alternating warm/pain task. The pain network activated by the painful heat stimuli when no attentional or emotional modulations are used is shown. Ipsi, Ipsilateral; Contra, contralateral. All figures depict neurological orientation (left is left). 
Table 2. Pain processing-related areas in the absence of attentional or emotional modulations

\begin{tabular}{lllr}
\hline Region (BA) & MNI coordinates & $t$ score & Cluster size \\
\hline Contralateral ACC & $8,14,34$ & $\mathbf{3 . 4 6 6}$ & 368 \\
Ipsilateral ACC & $-8,12,34$ & $\mathbf{3 . 5 6 8}$ & 216 \\
Contralateral insula & $32,16,8$ & $\mathbf{3 . 7 3 7}$ & $\mathbf{1 3 , 1 2 8}$ \\
& $42,6,-10$ & $\mathbf{4 . 7 7 3}$ & \\
& $42,-4,-2$ & $\mathbf{4 . 2 4 6}$ & \\
Contralateral S2 & $56,-14,14$ & $\underline{\mathbf{5 . 1 3 8}}$ & \\
& $62,-18,22$ & $\mathbf{4 . 1 1 1}$ & \\
Ipsilateral insula & $-44,2,2$ & $\mathbf{3 . 9 5 8}$ & $\mathbf{7 1 1 2}$ \\
& $-34,2,6$ & $\mathbf{3 . 4 3 8}$ & \\
& $-34,-2,10$ & $\mathbf{3 . 4 4 6}$ & \\
& $-42,-8,0$ & $\underline{\mathbf{4 . 8 0 6}}$ & \\
& $-42,-10,2$ & $\underline{\mathbf{4 . 8 2 0}}$ & \\
& $-42,-14,8$ & $\mathbf{4 . 3 9 4}$ & \\
Ipsilateral S2 & $-38,-16,18$ & $\mathbf{3 . 6 4 8}$ & \\
Contralateral medialTH & $-50,-24,22$ & $\mathbf{3 . 5 4 1}$ & $\mathbf{1 6 3 2}$ \\
& $6,-24,0$ & $\underline{\mathbf{5 . 5 3 2}}$ & $\mathbf{1 3 7 6}$ \\
Contralateral S1 & $2,-18,0$ & $\underline{\mathbf{4 . 8 3 9}}$ & \\
& $10,-42,64$ & $\mathbf{4 . 1 0 2}$ & $\mathbf{8 9 6}$ \\
& $14,-44,62$ & $\mathbf{3 . 9 1 6}$ &
\end{tabular}

Thalamic and cortical regions show increased BOLD response during the alternating warm/pain condition for the painful stimuli compared with warm nonpainful baseline. Cluster size refers to the size of the cluster in cubed millimeters with $t$ values superior to 2.5 . $t$ scores significant in global search are bolded and underlined. $t$ scores and cluster sizes significant in the directed search are indicated in bold.

during psychological modulation of pain or otherwise implicated in attentional or emotional processes. These areas were the PAG (Tracey et al., 2002; Valet et al., 2004), the inferior frontal cortex including the orbital parts (Esch and Stefano, 2004; Kringelbach, 2005; Petrovic et al., 2005), the ERC (Ploghaus et al., 2001), and the superior parietal cortex (Petersen et al., 1994; Hsieh et al., 1995; Corbetta and Shulman, 2002; Duncan and Albanese, 2003; Behrmann et al., 2004; Shomstein and Yantis, 2004, 2006; Fan et al., 2005; Hahn et al., 2006; Lepsien and Nobre, 2006). The volume of the different regions of interest (ROIs) were obtained by drawing each region on the average brain of the 14 subjects, except for frontal and S1 regions where sulcal anatomy was not clear enough in the average brain. For these two regions, individual brains were used. These volumes were used to calculate the threshold $t$ values for directed searches and extent thresholds for cluster analysis. Refer to Table 1 for the volumes, peak thresholds, and cluster size thresholds of the different ROIs.

\section{fMRI analysis for alternating warm/pain task}

In this task, we contrasted the brain activation evoked by pain (defined as the beginning of each painful temperature plateau plus $4 \mathrm{~s}$ ) with the brain activation evoked by the baseline temperature (defined as the $3.5 \mathrm{~s}$ period preceding the rise of pain) (Fig. 1). This represented the brain activity associated with heat pain for each subject. We then combined the scans of all subjects to obtain group statistical maps. Global and directed searches within the group statistical map permitted the identification of the thalamic and cortical areas representing the pain network susceptible to be modified by the attentional and emotional modulations in this study.

\section{fMRI analysis of discrimination task}

Identification of pain-processing areas. To determine brain regions activated by the painful stimuli, we compared the BOLD signal during pain with that during a contrast period of nonpainful temperature. Analyses were performed contrasting the first painful stimulus of each pair, the second painful stimulus of each pair, or all painful stimuli of the pairs with the $3.5 \mathrm{~s}$ period preceding the rise of either the first or second painful stimulus of the pair. Independent of whether we used the first, second, or both painful stimuli of the pairs, we found the most robust pain-evoked activation using the contrast period preceding the second stimulus of each pair. Furthermore, overall, using all painful stimuli generated higher $t$ values, so data presented below were determined by contrasting all painful stimuli to the period preceding the second stimuli of each pair (Fig. 2).
The contrast was obtained for all four experimental conditions (AHGO, AHBO, AOGO, and AOBO) for each subject. For each subject, we combined specific contrasts to obtain the brain activation associated with (1) attending heat regardless of odor type $(\mathrm{AH}=\mathrm{AHGO}+\mathrm{AHBO})$, (2) attending odors with pain present regardless of odor type $(\mathrm{AO}=$ $\mathrm{AOGO}+\mathrm{AOBO}),(3)$ good odor regardless of attention direction $(\mathrm{GO}=$ AOGO + AHGO), and (4) bad odor regardless of attention direction $(\mathrm{BO}=\mathrm{AOBO}+\mathrm{AHBO})$ and performed the following subtractions (1) $\mathrm{AH}-\mathrm{AO}$ and (2) $\mathrm{BO}-\mathrm{GO}$. The scans of all subjects for each of these contrasts were combined to obtain group statistical maps. Examination of the group statistical map of $\mathrm{AH}, \mathrm{AO}$, and $\mathrm{AH}-\mathrm{AO}$ identified the pain processing-related areas modulated by attention direction, whereas examination of $\mathrm{BO}, \mathrm{GO}$, and $\mathrm{BO}-\mathrm{GO}$ identified the pain processingrelated areas modulated by emotional context. For the subtraction maps, because we were testing unidirectional a priori hypotheses about the activation decrease caused by distraction or mood improvement related to the pleasant odors, we applied a threshold $t$ value of 1.771 ( $\mathrm{df}=13 ; p<$ 0.05 , single sided). This threshold $t$ value was adjusted for the number of subtractions being assessed in a given condition. For example, when evaluating four subtractions in a given condition, a threshold $t$ value of 2.533 was used $(\mathrm{df}=13 ; p<0.0125$, single sided $)$.

Identification of possible pain modulators. To identify brain areas possibly implicated in attentional and emotional pain modulation, we linearly weighted the BOLD signal with the subject's NRS ratings (for $\mathrm{AH}$, $\mathrm{AO}, \mathrm{BO}, \mathrm{GO}$ ) and changes in NRS ratings between conditions (for subtractions $\mathrm{AH}-\mathrm{AO}$ and $\mathrm{BO}-\mathrm{GO}$ ). Pain intensity scores were used as the weighting factor for the attentional condition involving the comparison of $\mathrm{AH}$ and $\mathrm{AO}$, because direction of attention primarily influences perceived pain intensity (Villemure et al., 2003). Pain unpleasantness scores were used as the weighting factor for the emotional modulation involving the comparison of BO and GO, because odor-evoked changes in mood primarily influence pain unpleasantness (Villemure et al., 2003). To consider a region modulatory for pain, we required that the activation in that region meet the following criteria: (1) the area was significantly activated in the individual conditions ( $\mathrm{AH}$ and $\mathrm{BO}$ ) when weighted with pain perception scores; and, most importantly, (2) the area was significantly activated in the subtractions ( $\mathrm{AH}-\mathrm{AO}$ and $\mathrm{BO}-\mathrm{GO}$ ) weighted with the change in pain perception. We refer to these regions as possible pain modulators.

\section{Covariation (functional connectivity) analyses}

Functional connectivity analyses can identify brain regions in which the BOLD response covaries with the activity of a selected reference voxel during a particular task. We were interested to see whether the activity in the key pain-processing regions modulated by the attentional and emotional manipulations covaried with the activity of regions identified as possible pain modulators. Covariation of the signal of the pain processing-related regions and the potential pain modulators would further support a functional link between the two. However, no causal relationship can be identified with this method. The key cortical area of the pain matrix modulated by mood was identified by comparing signals in $\mathrm{BO}$ and $\mathrm{GO}$ conditions. Individual peak activation levels within this area during the $\mathrm{BO}$ condition were measured and used as regressors (weighting factors) in a new model to estimate covariation. The $\mathrm{BO}$ condition was chosen over the $\mathrm{GO}$ condition or $\mathrm{BO}-\mathrm{GO}$ subtraction map because the pain processing-related signal was the strongest in $\mathrm{BO}$. A similar approach was performed for the attention modulation using the $\mathrm{AH}$ condition.

\section{Results}

\section{Psychophysical results}

\section{Selection of stimuli}

The temperatures that were determined in the preliminary session to be moderately painful ranged from 44 to $50^{\circ}$ (mean $\pm \mathrm{SD}$, $\left.46.8 \pm 1.5^{\circ} \mathrm{C}\right)$. The second temperature of the pair that was discriminated from the first $\sim 80 \%$ of the time was most commonly $1^{\circ} \mathrm{C}$ greater than this $\left(47.8 \pm 1.5^{\circ} \mathrm{C}\right)$. The average performance scores on the discrimination task were as follows (mean $\pm \mathrm{SE}$ ): AHGO, $83 \pm 3 \%$; AHBO, $85 \pm 3 \%$; AOGO, $72 \pm 4 \%$; AOBO, 
$57 \pm 5 \%$. There was no significant effect of the factor $\operatorname{ODOR}\left(F_{(1,13)}=3.78 ; p>0.07\right)$. There was a significant effect of the factor ATTENTION $\left(F_{(1,13)}=17.55 ; p<0.01\right)$ reflecting a better performance on the heat discrimination task $(84 \pm 2 \%)$ than on the odor discrimination task $(65 \pm 4 \%)$, but there was also a significant interaction between the factors ATTENTION and $\operatorname{ODOR}\left(F_{(1,13)}=5.46 ; p<0.04\right)$. The post hoc test (Tukey's HSD) shows that this was attributable to the poorer performance in AOBO compared with all other conditions (all $p<0.05$ ), whereas the performances in AHGO, AHBO, and AOGO were not significantly different from each other (all $p>0.09$ ). So, although the matching of task performance was not as successful in the scanner as during pretesting, the performances for all tasks were above chance and submaximal, indicating that the tasks were difficult enough to maximize attentional demand but not so difficult as to discourage the subject from performing the tasks.

\section{Influence of direction of attention}

Direction of attention (to pain or odor) significantly influenced pain intensity ratings. Subjects rated pain as more intense when they attended to it (main effect of factor ATTENTION: AH (mean \pm SE), $7.8 \pm 0.2 ; \mathrm{AO}, 6.5 \pm 0.4 ; F_{(1,13)}=13.46$; $p<0.01)$. Direction of attention did not significantly affect pain unpleasantness (main effect of factor ATTENTION: AH, $6.1 \pm 0.4 ; \mathrm{AO}, 5.3 \pm 0.5 ; F_{(1,13)}=3.13 ; p>$ 0.1 ; or interaction: $\left.F_{(1,13)}=0.40 ; p>0.5\right)$, mood (main effect of factor ATTENTION: $\mathrm{AH}, 1.9 \pm 0.7 ; \mathrm{AO}, 1.4 \pm 0.7 ; F_{(1,13)}=2.76$; $p>0.12$; or interaction between ATTENTION and ODOR: $\left.F_{(1,13)}=3.25 ; p>0.09\right)$, or anxiety/calmness (main effect of factor ATTENTION: AH, $-0.3 \pm 0.8 ; \mathrm{AO}$, $-0.5 \pm 0.8 ; F_{(1,13)}=0.16 ; p>0.7$; or interaction: $\left.F_{(1,13)}=3.31 ; p>0.09\right)$. This replicates our previous findings (Villemure et al., 2003).

\section{Influence of odor valence}

Odor valence (good vs bad odor) significantly influenced mood, anxiety/calmness, and pain unpleasantness but not pain intensity ratings. The thermal stimuli were rated as more unpleasant in the presence of the bad odor than the good odor (main effect of factor ODOR: BO, $6.3 \pm 0.5$; GO, $5.1 \pm$ $\left.0.5 ; F_{(1,13)}=6.95 ; p<0.05\right)$ but were not rated as more intense (main effect of factor ODOR: BO, $7.3 \pm 0.3 ; \mathrm{GO}, 6.9 \pm 0.4 ; F_{(1,13)}$ $=2.59 ; p>0.1$; or interaction: $\left.F_{(1,13)}=1.43 ; p>0.2\right)$. Mood was significantly better in the good odor condition (main effect of factor ODOR: BO, $-0.4 \pm 1.1 ; \mathrm{GO}, 3.7 \pm 0.6 ; F_{(1,13)}=13.76 ; p<$ $0.0027)$. Subjects were also calmer when the good odor was present (main effect of factor ODOR: $\mathrm{BO},-1.7 \pm 0.9$; GO, $0.9 \pm$

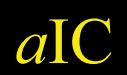

\section{Attentional modulation}

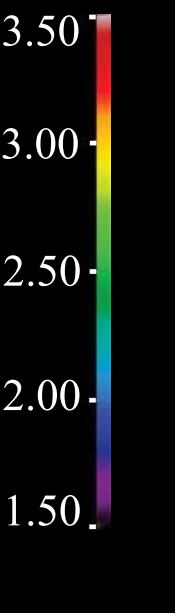

Figure 4. Attentional modulation network. Attentional effects within the previously identified pain network are observed in the alC. All figures depict neurological orientation (left is left).

Table 3. Pain processing-related areas modulated by the attentional and emotional tasks

\begin{tabular}{|c|c|c|c|c|}
\hline Region (BA) & Condition & MNI coordinates & $t$ score & Cluster size \\
\hline \multicolumn{5}{|l|}{ Attentional modulation } \\
\hline \multirow[t]{6}{*}{ Anterior insula } & $\mathrm{AH}$ & $-28,16,6$ & 4.310 & $1160^{*}$ \\
\hline & A0 & $-28,16,6$ & 1.105 & 0 \\
\hline & $\mathrm{AH}-\mathrm{AO}$ & $-28,14,6$ & 1.898 & 0 \\
\hline & $\mathrm{AH}$ & $-34,20,16$ & 3.579 & $1160^{*}$ \\
\hline & AO & $-34,20,16$ & 0.792 & 0 \\
\hline & $\mathrm{AH}-\mathrm{AO}$ & $-34,18,16$ & 1.898 & 0 \\
\hline \multicolumn{5}{|l|}{ Emotional modulation } \\
\hline \multirow[t]{6}{*}{ Contralateral ACC (BA24) } & BO & $6,4,34$ & 3.536 & $1800^{*}$ \\
\hline & GO & $6,4,34$ & -0.493 & 0 \\
\hline & $\mathrm{BO}-\mathrm{GO}$ & $6,6,30$ & 3.195 & $760^{*}$ \\
\hline & BO & $4,-4,32$ & 4.042 & $1800^{*}$ \\
\hline & GO & $4,-4,32$ & 0.090 & 0 \\
\hline & $\mathrm{BO}-\mathrm{GO}$ & $6,0,32$ & 3.434 & $760^{*}$ \\
\hline \multirow[t]{3}{*}{ medialTH } & BO & $2,-8,0$ & 3.871 & 208 \\
\hline & GO & $2,-8,0$ & -0.881 & 0 \\
\hline & $\mathrm{BO}-\mathrm{GO}$ & $-2,-8,0$ & 3.501 & 456 \\
\hline \multirow[t]{3}{*}{ Contralateral S2 } & BO & $52,-38,24$ & 3.754 & 432 \\
\hline & GO & $52,-38,24$ & -0.260 & 0 \\
\hline & $\mathrm{BO}-\mathrm{GO}$ & $52,-40,22$ & 3.242 & 96 \\
\hline \multirow[t]{3}{*}{ Contralateral S1 } & $\mathrm{BO}$ & $22,-38,62$ & 3.934 & 816 \\
\hline & GO & $20,-32,62$ & 2.677 & 32 \\
\hline & $\mathrm{BO}-\mathrm{GO}$ & $24,-38,58$ & 2.978 & 536 \\
\hline
\end{tabular}

Cluster size refers to the size of the cluster in cubed millimeters with $t$ values superior to 2.5. $t$ scores and cluster sizes significant in the directed search are Cluster size refers to the size of the cluster in cubed millimeters
indicated in bold. *Same cluster with more than one peak.

$\left.0.8 ; F_{(1,13)}=13.84 ; p<0.01\right)$. This replicates our previous findings (Villemure et al., 2003).

Stepwise linear regression analysis

Because odor hedonics was found to affect pain unpleasantness, mood, and anxiety, odor hedonics, mood, and anxiety changes were included as independent variables in a stepwise linear regression analysis to determine which best predicted changes in pain unpleasantness ratings. The only significant predictor of pain unpleasantness changes in the stepwise regression was mood changes $\left(R^{2}=\right.$ 


\section{Emotional modulation}

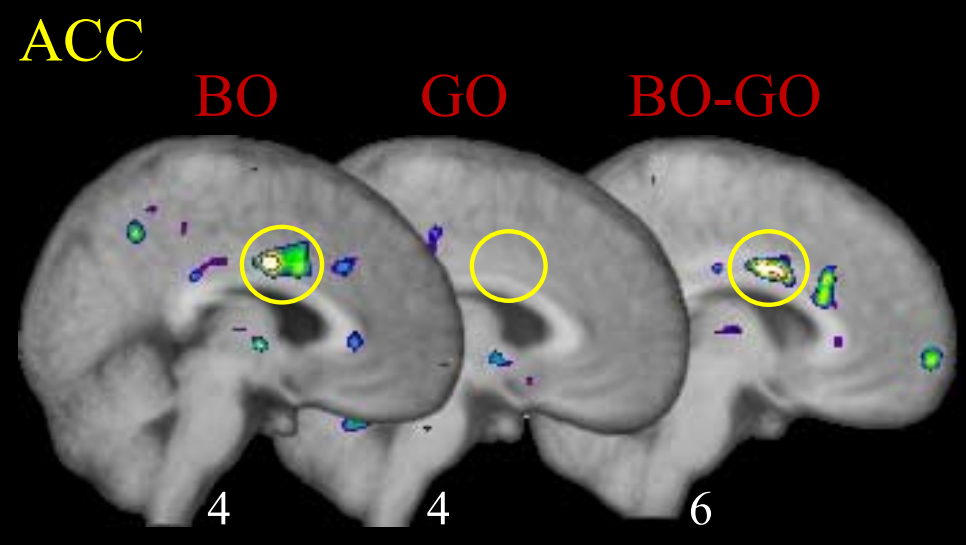

Thalamus
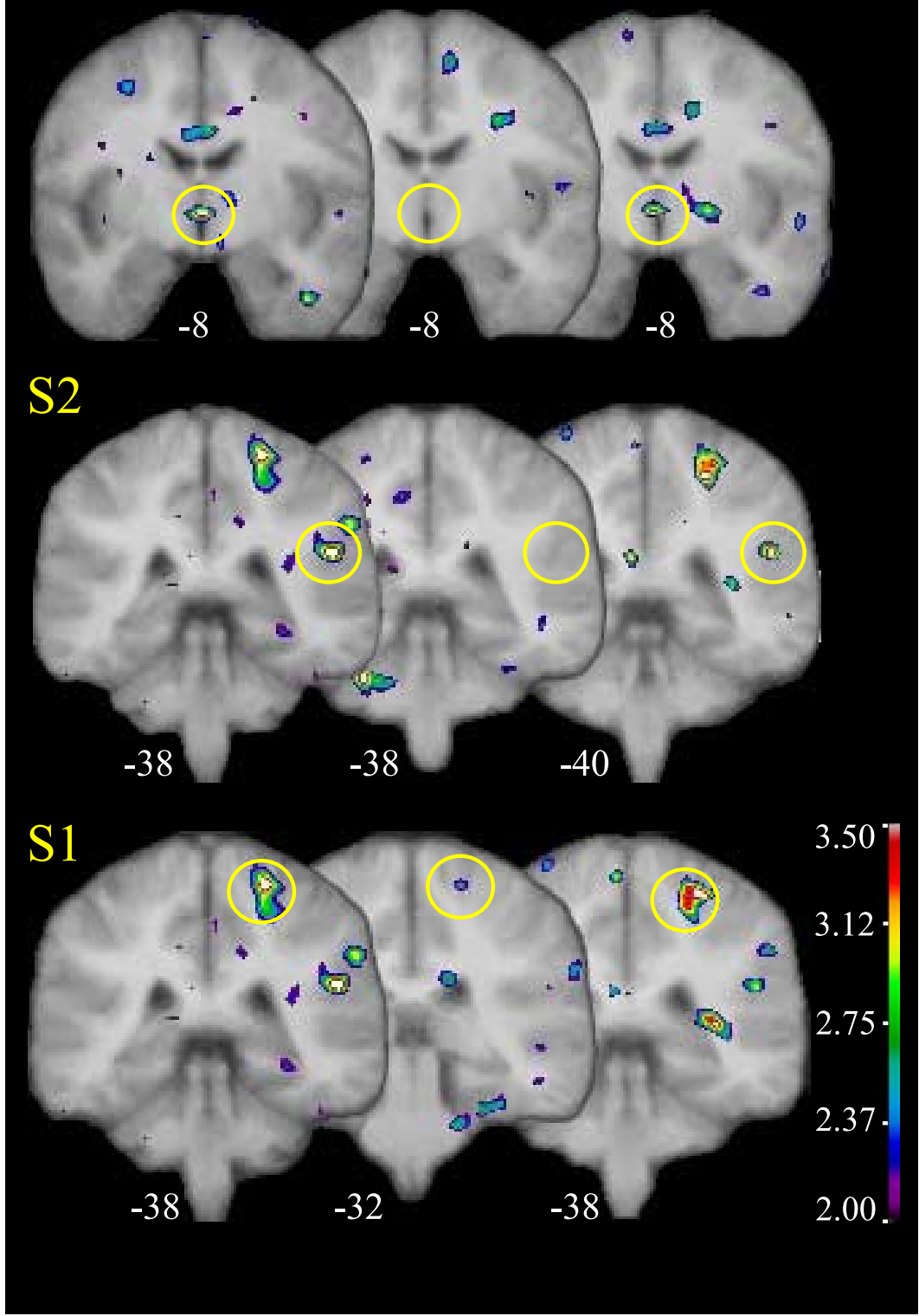

Figure 5. Emotional modulation network. Emotional effects within the previously identified pain network are observed in ACC, thalamus, S2, and S1. All figures depict neurological orientation (left is left). $\left.0.29 ; F_{(1,13)}=4.898 ; p<0.05\right)$. This suggests that effects of odors on pain unpleasantness were indeed mediated through mood changes.

\section{fMRI results}

Activation evoked by painful stimuli compared with warm stimuli

In the absence of attentional or emotional modulation, the following thalamic and cortical brain areas were activated by the painful heat stimuli: contralateral (right) medial thalamus (medialTH) and S1, bilateral S2, a large extent of midIC and aIC bilaterally, and bilateral ACC (Fig. 3, Table 2).

Pain processing areas modulated by direction of attention

Within the pain network identified previously, direction of attention altered painevoked activity only in the ipsilateral aIC (Fig. 4, Table 3). Activity in this area was significant both in terms of peak $t$ value and spatial extent when attending to pain (AH condition) but not when attending to odors (AO condition). In the subtraction map ( $\mathrm{AH}-\mathrm{AO})$, aIC activation did not reach the statistical criterion for a new discovery in this region (criterion $t=3.4171$ ) (Table 1) but met the one-tailed $t$ test criterion established to test the a priori hypothesis that the activation was stronger in $\mathrm{AH}$ than $\mathrm{AO}$.

Pain processing areas modulated by mood Pain-evoked activity was greater during the bad odor/worse mood (BO condition) than during the good odor/better mood (GO condition) in the contralateral ACC, medialTH, and contralateral S1 and S2 (Fig. 5, Table 3). In the subtraction map (BO - GO), all these activations reached the one-tailed $t$ test criterion established to test the a priori hypothesis that the activation was stronger in $\mathrm{BO}$ than GO and the statistical criterion for a new discovery in these regions (see Table 1 for the different thresholds) except for S2, which met only the former criterion.

\section{Possible pain modulators in}

attentional context

There was a significant superior posterior parietal (SPP; BA7) activation in the $\mathrm{AH}$ condition weighted with the pain intensity score and in the subtraction $\mathrm{AH}-\mathrm{AO}$ weighted with the change in the pain intensity score (Fig. 6A, Table 4). Additionally, there was a significant ERC (BA28) activation in $\mathrm{AH}$ condition weighted with the pain intensity score and in the $\mathrm{AH}-$ AO condition weighted with the change in pain intensity perception. Furthermore, in the $\mathrm{AH}$ condition, the activity of aIC pos- 
itively covaried with the activity of SPP (Fig. 6A, Table 5). There was a positive correlation between activity within aIC and ERC, but it did not reach statistical significance (Fig. 6A, Table 5).

Possible pain modulators in emotional context

The right LinfF gyrus orbital part (BA47) was significantly activated in the $\mathrm{BO}$ condition weighted with pain unpleasantness scores and in the $\mathrm{BO}-\mathrm{GO}$ condition weighted with the change in the pain unpleasantness score (Fig. 6B, Table 4). Additionally, there was a close to significant activation $\left(t_{\text {score }}=3.464\right.$; $\left.t_{\text {threshold }}=3.495\right)$ of the right LinfF gyrus triangular part (BA45/47) in the BO condition weighted with the pain unpleasantness score and a significant activation of this region in the subtraction $\mathrm{BO}-\mathrm{GO}$ weighted with the change in the pain unpleasantness score. Furthermore, in the BO condition, the activity of ACC positively covaried with the activity in LinfF cortex triangular and orbital parts (BA45/ 47) and PAG (Fig. 6B, Table 5).

\section{Discussion}

We found evidence of separate neural circuits underlying emotional and attentional pain modulation. Pleasant odors, independent of attentional focus, induced positive mood changes and decreased pain unpleasantness perception and painevoked activity in ACC, medialTH, S1, and S2. LinfF (BA45/47) activity correlated with the amount of pain modulation produced by emotional context and, ACC activity covaried with LinfF and PAG activity. Attending odors during pain decreased pain intensity perception and pain-evoked activity in aIC. SPP (BA7) and entorhinal activity correlated with the amount of pain modulation produced by attention direction, but aIC activity covaried only with SPP activity.

\section{Emotional modulation}

The ACC showed the largest mood modulation, but modulation also occurred in medialTH, S2, and S1. ACC activity was previously implicated in pain affect (Rainville et al., 1997; Tolle et al., 1999), consistent with our finding that odor-evoked mood changes preferentially modulate pain unpleasantness. The mood-related modulation in medialTH suggests that mood-related changes in nociceptive processing involve descending modulatory circuits affecting subcortical regions. S1 and S2 activity is most often attributed to sensory-discriminative aspects of pain

\section{a. Possible pain modulators in attentional condition}

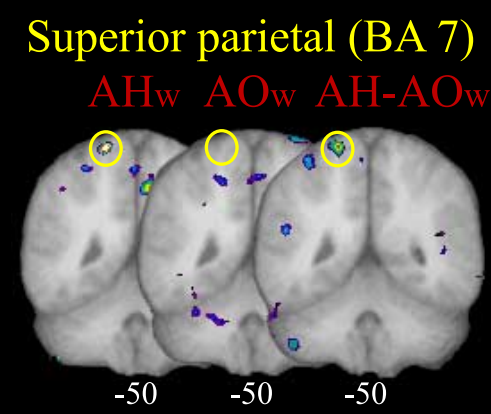

Entorhinal (BA 28)

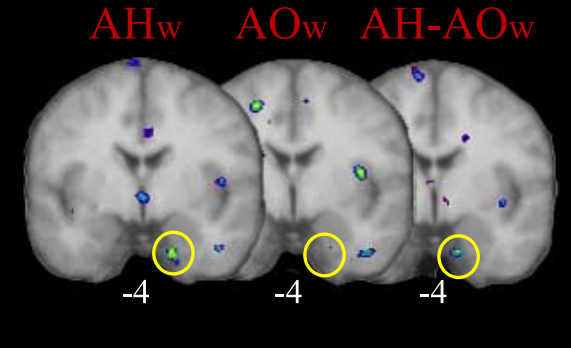

Possible pain modulators that covary with $a \mathrm{IC}$ in $\mathrm{AH}$
Superior parietal Entorhinal (n.s.)

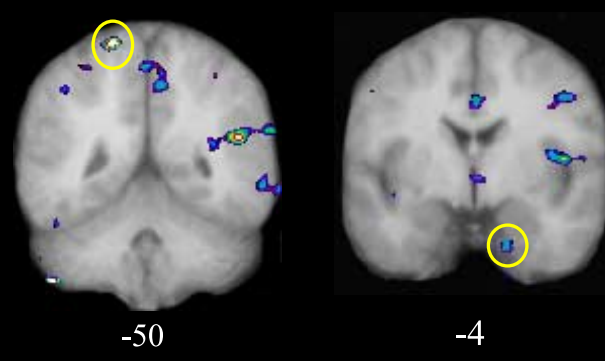

b. Possible pain modulators in emotional condition Lateral inferior frontal (BA 45/47)

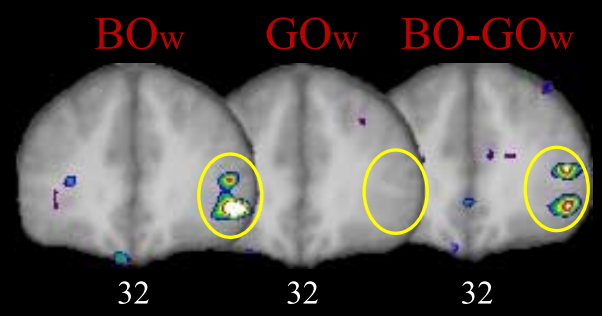

Possible pain modulators that covary with $\mathrm{ACC}$ in $\mathrm{BO}$
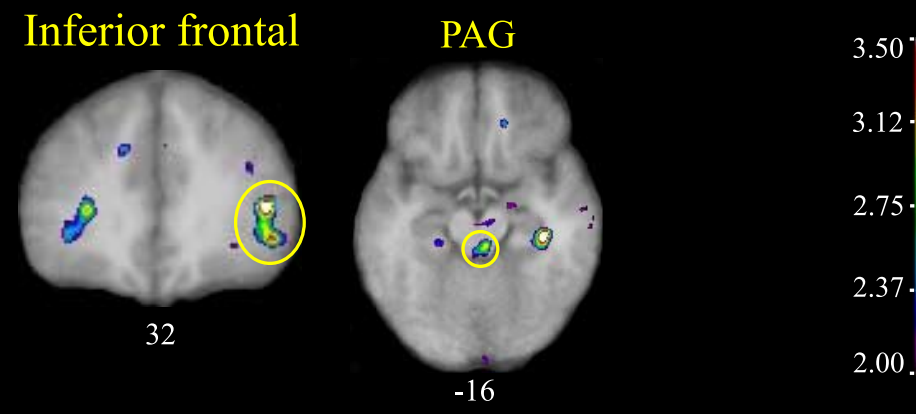

Figure 6. Possible pain modulating regions. A, Attentional condition weighted (w) with pain intensity scores for $A H$ w and $A 0 \mathrm{w}$ conditions and with the difference in pain intensity ratings between attentional conditions (NRS score in AH minus NRS score in A0) for the subtraction AH - AOw. Activity within the SPP (BA7) and the ERC (BA28) correlated with both the pain intensity ratings and the change in pain intensity ratings between attentional conditions. Activity within alC (the key perceptual region modulated by attention direction) covaried with superior parietal activity and, to a lesser degree (not statistically significant), with entorhinal activity in the $\mathrm{AH}$ condition. $\boldsymbol{B}$, Emotional condition weighted with pain unpleasantness scores for $\mathrm{BOW}$ and $\mathrm{GOW}$ conditions and with the difference in pain unpleasantness ratings between emotional conditions (NRS score in BO minus NRS score in $\mathrm{GO}$ ) for the subtraction BO - GOW. Activity within the LinfF, triangular and orbital parts (BA45/47), correlated with both the pain unpleasantness ratings and the change in pain unpleasantness ratings between emotional conditions. Activity within ACC (the key perceptual region modulated by mood) covaried with both the inferior frontal cortex and PAG activity in the BO condition. All figures depict neurological orientation (left is left). 
Table 4. Potential pain modulators associated with the attentional and emotional conditions

\begin{tabular}{|c|c|c|c|c|}
\hline Region (BA) & Condition & MNI coordinates & tscore & Cluster size \\
\hline \multicolumn{5}{|l|}{ Attentional modulation } \\
\hline \multirow[t]{3}{*}{$\operatorname{SPP}(B A 7)$} & $\mathrm{AHw}$ & $-18,-50,70$ & 4.362 & 208 \\
\hline & $\mathrm{A} 0 \mathrm{w}$ & $-18,-50,70$ & -1.375 & 0 \\
\hline & $\mathrm{AH}-\mathrm{AOW}$ & $-18,-50,70$ & 3.400 & 184 \\
\hline \multirow[t]{3}{*}{$\mathrm{ERC}(\mathrm{BA28})$} & $\mathrm{AHw}$ & $18,-4,-38$ & 3.335 & 80 \\
\hline & A0w & $18,-4,-38$ & 0.70 & 0 \\
\hline & $\mathrm{AH}-\mathrm{AOW}$ & $14,-4,-34$ & 3.171 & 104 \\
\hline \multicolumn{5}{|l|}{ Emotional modulation } \\
\hline \multirow[t]{3}{*}{ Inferior frontal gyrus —-triangular part (BA45/47) } & $\mathrm{BOw}$ & $46,32,10$ & $3.464^{* *}$ & 192 \\
\hline & GOW & $46,32,10$ & -0.507 & 0 \\
\hline & $\mathrm{B} 0-\mathrm{GOW}$ & $48,32,12$ & 3.633 & 376 \\
\hline \multirow[t]{3}{*}{ Inferior frontal gyrus — orbital part (BA47) } & BOw & $50,32,-4$ & $\underline{5.364}$ & 1336 \\
\hline & $\mathrm{GOW}$ & $50,32,-4$ & -1.364 & 0 \\
\hline & $\mathrm{B} 0-\mathrm{GOW}$ & $48,32,-6$ & 3.653 & 1344 \\
\hline
\end{tabular}

The $\mathrm{AH}$ and $\mathrm{A} 0$ conditions were weighted $(\mathrm{w})$ with pain intensity scores, whereas the $\mathrm{B} 0$ and $\mathrm{GO}$ conditions were weighted with pain unpleasantness scores. The subtractions were weighted with the change in pain intensity or unpleasantness ratings for the attention and emotion conditions, respectively. Cluster size refers to the size of the cluster in cubed millimeters with $t$ values superior to 2.5. $t$ scores significant in the directed search are indicated in bold. $t$ scores significant in global search are bolded and underlined. ${ }^{* *}$ Approaching significance.

Table 5. Covariation between the main pain processing-related areas modulated by attention (alC) or emotion (ACC) and potential pain modulators

\begin{tabular}{|c|c|c|c|c|}
\hline Region (BA) & Condition & MNI coordinates $(x, y, z)$ & $t$ score & Cluster size \\
\hline \multicolumn{5}{|l|}{ Attentional condition (areas that covary with alC) } \\
\hline alC & $\mathrm{AH}$ & $-28,16,6$ & $\underline{5.623}$ & 5336 \\
\hline $\mathrm{SPP}(\mathrm{BA7})$ & $\mathrm{AH}$ & $-18,-50,70$ & 4.333 & 224 \\
\hline ERC (BA28) & $\mathrm{AH}$ & $16,-4,-38$ & 2.761 & 40 \\
\hline \multicolumn{5}{|l|}{ Emotional condition (areas that covary with ACC) } \\
\hline \multirow[t]{2}{*}{$\mathrm{ACC}(\mathrm{BA24})$} & $\mathrm{BO}$ & $-2,10,32$ & 3.774 & $4672^{*}$ \\
\hline & $\mathrm{BO}$ & $4,-2,32$ & 5.981 & $4672^{*}$ \\
\hline Inferior frontal—-triangular part (BA45/47) & $\mathrm{BO}$ & $46,32,10$ & $\overline{4.158}$ & $752^{*}$ \\
\hline Inferior frontal_ — orbital part (BA47) & $\mathrm{BO}$ & $48,30,-4$ & 3.706 & $752^{*}$ \\
\hline PAG & $\mathrm{BO}$ & $6,-32,-16$ & 3.184 & 480 \\
\hline
\end{tabular}

Cluster size refers to the size of the cluster in cubed millimeters with $t$ values superior to 2.5 . $t$ scores and cluster sizes significant in the directed search are indicated in bold. $t$ scores significant in global search are bolded and underlined. *Same cluster with more than one peak.

perception. However, there are neural pathways connecting these regions to brain areas implicated in pain affect such as ACC (Price, 2000). Thus, S1 and S2 could indirectly participate in the affective dimension of pain through serial mechanisms by which sensory aspects of pain contribute to unpleasantness (Price, 2000).

We identified LinfF (BA47/BA45) as potential emotional pain modulators, because their activity correlated with changes in pain unpleasantness ratings between emotional conditions and covaried with ACC and PAG activity. Phillips et al. (2003) implicated BA45 in emotional modulation of nonpainful esophageal stimulation. The OFC, including BA47 in humans, receives input from all sensory modalities (including visceral) and has direct reciprocal connections with brain regions important for pain perception, such as ACC and PAG (Cavada et al., 2000; Kringelbach, 2005). Consequently, OFC is well placed to integrate sensory and visceral information, suggesting its involvement in emotional processing (Kringelbach, 2005). LateralOFC activity generally relates to negative emotions (Murphy et al., 2003) and evaluation of punishers, whereas medialOFC is implicated in reward (Kringelbach, 2005). Consistent with this idea, more lateralOFC activity was observed when pain was associated with unpleasant odors. Similarly, lateralOFC was activated when pain and thirst were experienced simultaneously, but not separately (Farrell et al., 2006).

Animal studies implicate the ventrolateralOFC in antinociception/analgesia, suggesting the effects are mediated through descending connections with PAG. This is consistent with our finding that PAG activity covaried with ACC and BA45/47 activity during emotional modulation. In humans, lateralOFC was also implicated in a variety of cognitively driven pain modulations. OFC, with its rostral ACC and brainstem connections, belongs to a network using cognitive cues to activate the endogenous opioid system (Petrovic et al., 2002). The relative activity increase in lateralOFC during pain could represent a source of cognitive modulation of emotional aspects of pain processing (Petrovic and Ingvar, 2002). Alternatively, this covariation between LinfF, ACC, and PAG could reflect descending pro-nociceptive facilitatory mechanisms (Lovick, 2008).

\section{Attentional modulation}

When subjects attended odors, painful stimuli evoked less aIC activation than when they attended pain. This finding is arguably weaker than the emotional context findings because aIC activation reached significance in an a priori hypothesis but not using a new discovery criterion. Nevertheless, the modulation of aIC is consistent with the literature on attentional pain modulation, in which insula modulation is often described (Longe et al., 2001; Bantick et al., 2002; Brooks et al., 2002; Hoffman et al., 2004; Seminowicz et al., 2004; Dunckley et al., 2007). Furthermore, our psychophysical data showing that attention preferentially altered pain intensity ratings are consistent with other data implicating aIC in thermal intensity perception (Coghill et al., 1999; Craig et al., 2000; Olausson et al., 2005).

SPP (BA7) was identified as a potential attentional pain modulator because its activity was related to the change in pain intensity between attentional conditions and covaried with aIC activity. Increased SPP activity corresponded to increased aIC activity.

A role of the PPC, including SPP (BA7), in pain attention has been suggested (Duncan and Albanese, 2003) but not demonstrated (Apkarian et al., 2005). Studies involving other sensory modalities implicate BA7 in attentional processes as part of a bilateral dorsal frontoparietal system involved in intentional attention orienting (Petersen et al., 1994; Corbetta and Shulman, 2002; Shomstein and Yantis, 2004, 2006; Hahn et al., 2006; Lepsien and Nobre, 2006) and focused attention (Pardo et al., 1991; Burton and Sinclair, 2000; Behrmann et al., 2004; Nebel et al., 2005). Attentional orienting can bias information processing, optimizing cortical representation and thus perception of relevant information (Yantis and Serences, 2003; Lepsien and Nobre, 2006). Superior parietal activity would enhance activity within sensory cortices (Wu et al., 2007), possibly synchronizing the spiking activity in targeted neurons representing the attended object, thus driving more effective representations (Yantis and Serences, 2003). Attending painful stimuli could increase parietal activity leading to better processing of those stimuli, reflected by increased aIC activity and pain intensity perception.

A positron emission tomography study showing increased re- 
gional cerebral blood flow in PPC in chronic pain patients provides additional evidence for a role of PPC in attentional aspects of pain processing (Hsieh et al., 1995). The authors suggested that PPC activation during chronic pain may reflect increased attention and vigilance that patients devote to their condition.

Our data suggest an involvement of ERC in attentional pain modulation, because ERC activity correlated with the amount of pain modulation produced by attention direction. However, this must be interpreted with caution, because the correlation between the activities of aIC and ERC failed to reach significance. When weighing the data by magnitude of attention-related perceptual changes, we found that ERC was preferentially activated when subjects attended pain. Other studies have implicated ERC in attentional processes, particularly in relation to its connections with PPC (Burwell, 2000). This contrasts with the results of Ploghaus et al. (2001), who reported ERC's involvement in emotional pain modulation. They compared brain activity evoked by mildly painful stimuli during a condition in which subjects were certain that they would receive mild pain (low anxiety) and a condition in which they knew they might equally well receive an intense pain (high anxiety). However, because no direct measures of anxiety or attention were taken, it is equally feasible that subjects were more attentive to the stimulus in the uncertain than in the certain condition. We cannot exclude that some ERC areas are associated with emotional pain modulation and others with attentional modulation because our peak activity was more anterior than theirs.

Some neuroimaging studies involving pain and different types of distraction implicated PAG in attentional pain modulation. Tracey et al. (2002) observed that PAG activation increased significantly when subjects used thoughts to distract themselves. Valet et al. (2004), using the incongruent color-word-Stroop as the distractor, observed that PAG activation correlated with prefrontal activity during the distraction task. Despite the apparently consistent observations, these distraction tasks could easily have changed arousal, mood, anxiety, or other emotional factors. In our study, we found PAG activity related to mood but not attention. Our results suggest that the previous reports of PAG involvement in distraction-related pain modulation could involve emotional differences between conditions. This interpretation is supported by Valet et al. (2004) finding that pain unpleasantness was more profoundly modulated than pain intensity, as observed during emotional pain modulation (Zelman et al., 1991; Villemure et al., 2003; Rainville et al., 2005). PAG activity correlates with anxiety during painful visceral stimulation (Dunckley et al., 2005) and, in other sensory modalities, is related to emotions such as "chills" associated with intensely pleasurable music (Blood and Zatorre, 2001). Finally, studies of directed attention involving vision, hearing, or touch fail to observe attentionrelated PAG activation but report activation in PPC similar to the attention-related activations in our study (Petersen et al., 1994; Burton and Sinclair, 2000; Behrmann et al., 2004; Shomstein and Yantis, 2004, 2006; Fan et al., 2005; Hahn et al., 2006).

\section{Limitations}

Choosing an appropriate contrast period for fMRI analysis presented a difficulty. We chose the ISI in favor of the expectation period before the stimulus pair, because it revealed more robust activation patterns. Nevertheless, possible expectancy and/or memory traces during ISI (Albanese et al., 2007) probably limited sensitivity, so that activations could have been present but not detected. This likely explains why we did not detect significant S1 activation or attention modulation in S1, contrasting with our previous studies (Bushnell et al., 1999).

Some studies showed that activity in parts of ACC correlates with odor-subjective pleasantness and unpleasantness (Rolls et al., 2003; Grabenhorst et al., 2007). This raises the possibility that the change in ACC activation we observed when pain is experienced with either pleasant or unpleasant odors could also reflect a change in the response to odors. However, ACC activity correlating with the subjective hedonic quality of odors was found considerably more rostrally $(y=28,42)$ than our observed ACC modulation and, as such, is unlikely to contribute to moodrelated modulation of nociceptive responses in ACC.

Finally, all pain reports were taken immediately after each scanning run and not after each individual stimulus. Because each run lasted for $\sim 5$ min, these summary ratings could be influenced by memory and differ from those taken after each stimulus. Nevertheless, a short delay between a pain stimulus and its rating is likely not problematic (Seminowicz and Davis, 2007). Furthermore, we have observed attentional modulation of almost the exact same magnitude with pain ratings acquired after each stimulus (Miron et al., 1989).

In conclusion, our findings suggest that emotional and attentional modulations invoked mostly separable brain networks. Emotional context preferentially modulated pain unpleasantness and modified activity in ACC, medialTH, S1, and S2, with LinfF and PAG identified as possible emotion-related pain modulators. Attentional context preferentially modulated pain intensity and activity within aIC. SPP and ERC were identified as possible sources of attention-related modulation.

\section{References}

Albanese MC, Duerden EG, Rainville P, Duncan GH (2007) Memory traces of pain in human cortex. J Neurosci 27:4612-4620.

Apkarian AV, Bushnell MC, Treede RD, Zubieta JK (2005) Human brain mechanisms of pain perception and regulation in health and disease. Eur J Pain 9:463-484.

Bantick SJ, Wise RG, Ploghaus A, Clare S, Smith SM, Tracey I (2002) Imaging how attention modulates pain in humans using functional MRI. Brain 125:310-319.

Behrmann M, Geng JJ, Shomstein S (2004) Parietal cortex and attention. Curr Opin Neurobiol 14:212-217.

Blood AJ, Zatorre RJ (2001) Intensely pleasurable responses to music correlate with activity in brain regions implicated in reward and emotion. Proc Natl Acad Sci U S A 98:11818-11823.

Brooks JC, Nurmikko TJ, Bimson WE, Singh KD, Roberts N (2002) fMRI of thermal pain: effects of stimulus laterality and attention. Neuroimage 15:293-301.

Buffington AL, Hanlon CA, McKeown MJ (2005) Acute and persistent pain modulation of attention-related anterior cingulate fMRI activations. Pain 113:172-184.

Burton H, Sinclair RJ (2000) Attending to and remembering tactile stimuli: a review of brain imaging data and single-neuron responses. J Clin Neurophysiol 17:575-591.

Burwell RD (2000) The parahippocampal region: corticocortical connectivity. Ann N Y Acad Sci 911:25-42.

Bushnell MC, Duncan GH, Hofbauer RK, Ha B, Chen JI, Carrier B (1999) Pain perception: is there a role for primary somatosensory cortex? Proc Natl Acad Sci U S A 96:7705-7709.

Cao J (1999) The size of the connected components of excursion sets of chi(2), t and F fields. Adv Appl Prob 31:579-595.

Cavada C, Company T, Tejedor J, Cruz-Rizzolo RJ, Reinoso-Suarez F (2000) The anatomical connections of the macaque monkey orbitofrontal cortex. A review. Cereb Cortex 10:220-242.

Coghill RC, Sang CN, Maisog JM, Iadarola MJ (1999) Pain intensity processing within the human brain: a bilateral, distributed mechanism. J Neurophysiol 82:1934-1943.

Collins DL, Neelin P, Peters TM, Evans AC (1994) Automatic 3D intersub- 
ject registration of MR volumetric data in standardized Talairach space. J Comput Assist Tomogr 18:192-205.

Corbetta M, Shulman GL (2002) Control of goal-directed and stimulusdriven attention in the brain. Nat Rev Neurosci 3:201-215.

Craig AD, Chen K, Bandy D, Reiman EM (2000) Thermosensory activation of insular cortex. Nat Neurosci 3:184-190.

Duncan GH, Albanese MC (2003) Is there a role for the parietal lobes in the perception of pain? Adv Neurol 93:69-86.

Dunckley P, Wise RG, Fairhurst M, Hobden P, Aziz Q, Chang L, Tracey I (2005) A comparison of visceral and somatic pain processing in the human brainstem using functional magnetic resonance imaging. J Neurosci 25:7333-7341.

Dunckley P, Aziz Q, Wise RG, Brooks J, Tracey I, Chang L (2007) Attentional modulation of visceral and somatic pain. Neurogastroenterol Motil 19:569-577.

Esch T, Stefano GB (2004) The neurobiology of pleasure, reward processes, addiction and their health implications. Neuro Endocrinol Lett 25:235-251.

Fan J, McCandliss BD, Fossella J, Flombaum JI, Posner MI (2005) The activation of attentional networks. Neuroimage 26:471-479.

Farrell MJ, Egan GF, Zamarripa F, Shade R, Blair-West J, Fox P, Denton DA (2006) Unique, common, and interacting cortical correlates of thirst and pain. Proc Natl Acad Sci U S A 103:2416-2421.

Frankenstein UN, Richter W, McIntyre MC, Remy F (2001) Distraction modulates anterior cingulate gyrus activations during the cold pressor test. Neuroimage 14:827-836.

Grabenhorst F, Rolls ET, Margot C, da Silva MA, Velazco MI (2007) How pleasant and unpleasant stimuli combine in different brain regions: odor mixtures. J Neurosci 27:13532-13540.

Hahn B, Ross TJ, Stein EA (2006) Neuroanatomical dissociation between bottom-up and top-down processes of visuospatial selective attention. Neuroimage 32:842-853.

Hoffman HG, Richards TL, Coda B, Bills AR, Blough D, Richards AL, Sharar SR (2004) Modulation of thermal pain-related brain activity with virtual reality: evidence from fMRI. Neuroreport 15:1245-1248.

Hsieh JC, Belfrage M, Stone-Elander S, Hansson P, Ingvar M (1995) Central representation of chronic ongoing neuropathic pain studied by positron emission tomography. Pain 63:225-236.

Kringelbach ML (2005) The human orbitofrontal cortex: linking reward to hedonic experience. Nat Rev Neurosci 6:691-702.

Lepsien J, Nobre AC (2006) Cognitive control of attention in the human brain: insights from orienting attention to mental representations. Brain Res 1105:20-31.

Longe SE, Wise R, Bantick S, Lloyd D, Johansen-Berg H, McGlone F, Tracey I (2001) Counter-stimulatory effects on pain perception and processing are significantly altered by attention: an fMRI study. Neuroreport 12:2021-2025.

Lovick TA (2008) Pro-nociceptive action of cholecystokinin in the periacqueductal grey: a role in neuropathic and anxiety-induced hyperalgesic states. Neurosci Biobehav Rev 32:852-862.

Mesulam MM (1998) From sensation to cognition. Brain 121:1013-1052.

Miron D, Duncan GH, Bushnell MC (1989) Effects of attention on the intensity and unpleasantness of thermal pain. Pain 39:345-352.

Murphy FC, Nimmo-Smith I, Lawrence AD (2003) Functional neuroanatomy of emotions: a meta-analysis. Cogn Affect Behav Neurosci 3:207-233.

Nebel K, Wiese H, Stude P, de GA, Diener HC, Keidel M (2005) On the neural basis of focused and divided attention. Brain Res Cogn Brain Res 25:760-776.

Olausson H, Charron J, Marchand S, Villemure C, Strigo IA, Bushnell MC (2005) Feelings of warmth correlate with neural activity in right anterior insular cortex. Neurosci Lett 389:1-5.

Pardo JV, Fox PT, Raichle ME (1991) Localization of a human system for sustained attention by positron emission tomography. Nature 349:61-64.

Petersen SE, Corbetta M, Miezin FM, Shulman GL (1994) PET studies of parietal involvement in spatial attention: comparison of different task types. Can J Exp Psychol 48:319-338.

Petrovic P, Ingvar M (2002) Imaging cognitive modulation of pain processing. Pain 95:1-5.

Petrovic P, Petersson KM, Ghatan PH, Stone-Elander S, Ingvar M (2000) Pain-related cerebral activation is altered by a distracting cognitive task. Pain 85:19-30.

Petrovic P, Kalso E, Petersson KM, Ingvar M (2002) Placebo and opioid analgesia-imaging a shared neuronal network. Science 295:1737-1740.
Petrovic P, Dietrich T, Fransson P, Andersson J, Carlsson K, Ingvar M (2005) Placebo in emotional processing-induced expectations of anxiety relief activate a generalized modulatory network. Neuron 46:957-969.

Peyron R, Garcia-Larrea L, Gregoire MC, Costes N, Convers P, Lavenne F, Mauguiere F, Michel D, Laurent B (1999) Haemodynamic brain responses to acute pain in humans: sensory and attentional networks. Brain 122:1765-1780.

Phillips ML, Gregory LJ, Cullen S, Coen S, Ng V, Andrew C, Giampietro V, Bullmore E, Zelaya F, Amaro E, Thompson DG, Hobson AR, Williams SC, Brammer M, Aziz Q (2003) The effect of negative emotional context on neural and behavioural responses to oesophageal stimulation. Brain 126:669-684.

Ploghaus A, Narain C, Beckmann CF, Clare S, Bantick S, Wise R, Matthews PM, Rawlins JN, Tracey I (2001) Exacerbation of pain by anxiety is associated with activity in a hippocampal network. J Neurosci 21:9896-9903.

Price DD (2000) Psychological and neural mechanisms of the affective dimension of pain. Science 288:1769-1772.

Price DD, McGrath PA, Rafii A, Buckingham B (1983) The validation of visual analogue scales as ratio scale measures for chronic and experimental pain. Pain 17:45-56.

Rainville P, Duncan GH, Price DD, Carrier B, Bushnell MC (1997) Pain affect encoded in human anterior cingulate but not somatosensory cortex. Science 277:968-971.

Rainville P, Bao QV, Chretien P (2005) Pain-related emotions modulate experimental pain perception and autonomic responses. Pain 118:306-318.

Rolls ET, Kringelbach ML, de Araujo IE (2003) Different representations of pleasant and unpleasant odours in the human brain. Eur J Neurosci 18:695-703.

Seminowicz DA, Davis KD (2007) A re-examination of pain-cognition interactions: implications for neuroimaging. Pain 130:8-13.

Seminowicz DA, Mikulis DJ, Davis KD (2004) Cognitive modulation of pain-related brain responses depends on behavioral strategy. Pain 112:48-58.

Shomstein S, Yantis S (2004) Control of attention shifts between vision and audition in human cortex. J Neurosci 24:10702-10706.

Shomstein S, Yantis S (2006) Parietal cortex mediates voluntary control of spatial and nonspatial auditory attention. J Neurosci 26:435-439.

Tolle TR, Kaufmann T, Siessmeier T, Lautenbacher S, Berthele A, Munz F, Zieglgansberger W, Willoch F, Schwaiger M, Conrad B, Bartenstein P (1999) Region-specific encoding of sensory and affective components of pain in the human brain: a positron emission tomography correlation analysis. Ann Neurol 45:40-47.

Tracey I, Ploghaus A, Gati JS, Clare S, Smith S, Menon RS, Matthews PM (2002) Imaging attentional modulation of pain in the periacqueductal gray in humans. J Neurosci 22:2748-2752.

Valet M, Sprenger T, Boecker H, Willoch F, Rummeny E, Conrad B, Erhard P, Tolle TR (2004) Distraction modulates connectivity of the cingulo-frontal cortex and the midbrain during pain-an fMRI analysis. Pain 109:399-408.

Villemure C, Bushnell MC (2002) Cognitive modulation of pain: how do attention and emotion influence pain processing? Pain 95:195-199.

Villemure C, Slotnick BM, Bushnell MC (2003) Effects of odors on pain perception: deciphering the roles of emotion and attention. Pain 106:101-108.

Wiech K, Seymour B, Kalisch R, Stephan KE, Koltzenburg M, Driver J, Dolan RJ (2005) Modulation of pain processing in hyperalgesia by cognitive demand. Neuroimage 27:59-69.

Worsley KJ, Marrett S, Neelin P, Vandal AC, Friston KJ, Evans AC (1996) A unified statistical approach for determining significant signals in images of cerebral activation. Human Brain Mapping 4:58-73.

Worsley KJ, Liao CH, Aston J, Petre V, Duncan GH, Morales F, Evans AC (2002) A general statistical analysis for fMRI data. Neuroimage 15:1-15.

Wu CT, Weissman DH, Roberts KC, Woldorff MG (2007) The neural circuitry underlying the executive control of auditory spatial attention. Brain Res 1134:187-198.

Yantis S, Serences JT (2003) Cortical mechanisms of space-based and object-based attentional control. Curr Opin Neurobiol 13:187-193.

Zelman DC, Howland EW, Nichols SN, Cleeland CS (1991) The effects of induced mood on laboratory pain. Pain 46:105-111. 